\title{
Percepción Actoral: formación inicial del actor en la Escuela de Teatro de la Pontificia Universidad Católica de Chile
}

Alexei Vergara Aravena*

\begin{abstract}
RESUMEN: El texto expone desde una perspectiva profesoral los fundamentos, trayectoria, objetivos y vicisitudes del trabajo del curso Percepción Actoral impartido en la Escuela de Teatro de la Pontificia Universidad Católica de Chile. Centrándose en el ámbito corporal, muestra en un primer punto las conceptualizaciones que animan tal ejercicio académico, como también los planteamientos metodológicos que guían esta labor, así como las problemáticas que se desprenden de un curso de jóvenes que debe moverse en dos dimensiones definidas: contacto con su cuerpo y yo perceptual y con la realidad social. En el primer caso se trata de explorar la memoria física y emotiva; mientras que en el segundo caso el camino es la selección de un territorio de materialidades desplegadas en la textura social -las más de las veces popular- de la ciudad.
\end{abstract}

Palabras clave: percepción, observación, formación de actores

\section{Origen y estatus del curso "Percepción Actoral”}

El curso "Percepción Actoral" se dicta desde 1969 y hasta la fecha durante el primer semestre de la carrera de Actuación en la Escuela de Teatro de la Pontificia Universidad Católica de Chile. Independientemente de los cambios curriculares que se han llevado a cabo en los últimos

\footnotetext{
*Alexei Vergara es profesor asistente de la Escuela de Teatro de la Pontificia Universidad Católica de Chile. Actor, Licenciado en Actuación y Magíster en Actor Training and Coaching, Royal Central School of Speech and Drama. Universidad de Londres. E mail: avergarb@uc.cl
} 
tiempos, este curso ha permanecido como inicio de un trayecto, debido a la importancia que se le atribuye como base para la formación de actores. Tiene su origen en un período convulsionado de la historia de Chile, cuyos hitos más significativos fueron las manifestaciones estudiantiles y las ocupaciones de planteles universitarios iniciadas el año 1967, el nacimiento de la creación colectiva como una nueva forma de hacer teatro social y de denuncia, así como la implantación de una dictadura cívico-militar que solo llegó a su fin en 1989.

El curso, luego, se inserta en una tradición que marca a esta Escuela, y que no se da en otros lugares universitarios o academias dedicadas a la formación de actores en Chile. Como asignatura representa el diseño de un punto de inflexión donde se manifiestan y definen las bases de los diferentes campos en los que está fundamentado el arte de la actuación; lo que nuestra unidad académica ha definido como centro fundamental del aprendizaje teatral, donde se manifiestan las grandes interrogantes sobre las líneas directrices en las que se cimienta nuestra escuela y se establece la visión que se ha considerado para articular todo el plan pedagógico posterior.

\section{Definiciones y metodologías}

Lo que inicialmente surge como interrogación es ¿por qué no es exactamente un primer curso de actuación? ¿Por qué debe ser algo previo para luego abordar las diferentes técnicas y estilos de actuación? ¿Por qué entonces se decretó como la primera experiencia académica fundamental que los estudiantes deben cursar y ser aprobados?

Más allá de la importancia de ser la primera etapa formativa, se trata de un espacio previo a las técnicas habituales de la interpretación que dice relación con exploraciones corporales, lúdicas, para que el estudiante tome confianza, aprenda a relacionarse con sus compañeros en forma desinhibida y, obviamente, tome conciencia profesional de su propio cuerpo.

En los orígenes del actual currículo de esta Escuela se determinó que era necesario definir un campo de experiencia previo para comprender los conceptos fundamentales en el desarrollo de un actor: la comprensión que él deberá tener del conflicto dramático en los textos y de los mecanismos para abordarlos técnicamente. Un campo de experiencias previas que se necesita para abordar lo que habitualmente se entiende como aprendizaje del actor, tanto en sus bases orgánicas y emotivas, como también en su comprensión y participación del medio teatral 
en sus diferentes vertientes. Este campo de experiencia desarrollado en el curso implica dotar al estudiante de un marco de vivencias significativas en la vinculación con el mundo social, lo que sitúa al aprendiz en el plano de la investigación de segundo orden, enfatizando en la capacidad de percepción y empatía con el mundo social; y constituyendo su quehacer artístico en base al propio mundo social, meditado e internalizado en el propio mundo del actor, es decir en su propio marco referencial. Esto significa más que interpretar información proveniente de un entorno por medio de los sentidos, la elaboración de un mecanismo de resignificación e internalización del contexto de lo sensible bajo premisas que pueden ser apoyadas, entre otras dimensiones culturales, por las ciencias sociales y que permitan la abstracción de lo percibido y vivenciado, avanzando desde lo recolectado a la creación dramática. El teatro siempre es, al fin y al cabo, creación desde la ficcionalidad, pero será diferente cuando se diseña y legitima un primer campo donde la creación deba ser en base a la percepción, a los sentidos y la estructura orgánica que entrega el cuerpo.

Esto significa que el joven estudiante de actuación en el entrenamiento recibido en aula, logra reconocer y desarrollar la capacidad de elaborar e interpretar la información y la realidad social desde el mismo contexto en que la recoge. Esto implica un proceso intersubjetivo, es decir, la vivencia individual en un mundo compartido, un mundo cruzado en la experiencia con los otros, remitiendo a las interacciones entre un yo y un otro que se encuentra allá, fuera de él, en el mundo de la vida social.

Aquí la intersubjetividad se entiende como la manera en que se logra entender al otro a partir de la implicancia con el mundo que rodea y envuelve al sujeto, a partir de la interacción y observación de su contexto social. Se echa mano así al concepto de empatía: se comprende al otro en la medida en que hay un intento por ponerse en su lugar, conectándose con sus sentimientos y entrando en su universo de significación al identificarse con él y su entorno.

Este yo del joven estudiante-actor contiene los impulsos psíquicos y emotivos que orientan las múltiples posibilidades de poner atención a un determinado fenómeno de lo social, que por medio de un entrenamiento dirigido en el curso posibilite la creación de una experiencia artística. La realidad social y, por tanto, no ficcionada, contiene mundos, espacios y situaciones que existen en el mundo de lo dado y que, aun cuando han inspirado los textos que los estudiantes deben ejecutar, no son textos, son la realidad. Pareciera ser que a medida que el estudiante de 
actuación y por extensión el actor, aprende y desarrolla su oficio debiera ser menos él mismo y más el personaje, siempre bajo las premisas y coordenadas de una estética escénica, de un texto dramático, de la creación de un mundo ficcional.

Sin embargo, se decidió comenzar por lo opuesto: no hay personaje y tanto el mundo como la estética determinada por la ficción del texto, es sustituida por la realidad en sus manifestaciones dramáticas: mundos, situaciones, personas, que día a día están socialmente operando. Así, la atención está anclada al yo corporal que percibe, en el actor que debe significar desde lo real, no en base a lo ficticio del texto.

\section{La percepción}

Ahora bien, la percepción se nos presenta como un proceso dicotómico que integra el adentro y el afuera del cuerpo del actor. El adentro es el mundo de la sensorialidad del estudiante desde su propia conciencia y vivencias; y el afuera es lo social, lo no ficcional. Esto implica tres etapas de entrenamiento y de aprendizaje: 1) el mundo de la exploración personal-sensorial que conecta el cuerpo con las emociones, donde el uso de la memoria física y emotiva tienen un objetivo y una práctica diferente a la habitual; 2) un extenso trabajo de investigación en terreno definiendo un ámbito concreto de la realidad, que se logra por medio de la inserción en el contexto de los individuos observados; 3) la dramaturgización y escenificación de este trabajo en sus diferentes fases secuenciales.

Tanto en el caso de las memorias físicas como en de las memorias emotivas, nuestro planteamiento y ejercitación no busca contactar solo con lo sensible para abordar desde la organicidad del cuerpo situaciones o emociones de la experiencia personal que después permitirían al estudiante aplicarlas a situaciones y personajes en diferentes escenas de autor (el proceso habitual inicial aprendizaje). En nuestro trabajo, la memoria física y emotiva están dirigidas a un reconocimiento desde el cuerpo a lo perceptual. Pero como ámbito y experiencia legitimada en sí misma y todo el tiempo dirigido al yo. Lo perceptual es primeramente un campo que tiene un valor en sí mismo y su aplicación está dirigida al yo que en este diseño no es el del autoconocimiento producido por medio de la rememoración: que reproduce nuevamente la significación de algo experienciado y la memoria vuelve a iluminarse. Ese yo es el campo donde se instala progresivamente la capacidad sensible de ver, que en este caso es percibir, es decir, asumiendo toda la complejidad que tal expresión significa. En el caso del actor 
significa reconocer sensorialmente en sí mismo el yo un complejo tramado de emociones e imágenes en el cuerpo que surgen de la experiencia personal, pero que deben estar al mismo tiempo profundamente conectadas con aquello que este tramado de emociones e imágenes ha captado y luego ha seleccionado de una situación de la vida social exterior. Ver, entonces, es ir reproduciendo a través de un entrenamiento del cuerpo todos los resortes que efectivamente provocaron y definieron una experiencia -exactamente esa y no otra- en una situación o evento concreto de la vida social exterior al contexto del que observa. Así, el entrenamiento físico y emotivo de la memoria genera una percepción aproximada de la vida social, capaz de focalizar, aquello que constituye la raíz dramática que existe en la vida cotidiana y que, en una experiencia personal concreta del observador, ha determinado lo realmente dramático de esta. Percibir, entonces, desde la experiencia personal que se ha reproducido en el cuerpo física y emocionalmente en el aula, es ver internamente: seleccionar y por tanto aprender a reconocer dónde ha estado lo dramático y dónde no. En este contexto, pensamos que sin esta capacidad inicial es imposible para un actor abordar cualquier creación, aun cuando tenga capacidades interpretativas naturales o cuando las premisas del personaje y sus conflictos pudieran estar señaladas dramáticamente en el texto que se va a montar. Aunque el director pudiera en última instancia y eficazmente hacerse cargo de todo esto. Una vez acreditado este aprendizaje orgánico de reconocimiento en el yo de lo dramático de la vida -en el campo de una experiencia personal- es necesario plantear un siguiente campo de trabajo, donde esta experiencia se desarrolle en el ámbito de la vida que ya no es personal, sino social. Lo social es un mundo que nos precede, que nos está siempre dado como un mundo organizado. Los alcances de este mundo social nos interesan en cuanto determinan nuestra orientación dentro de él, y por tanto las diferentes formas que hay de habitar en él, con toda la variedad de identidades culturales, objetos, nominaciones y sentidos sociales y culturales que existen en un determinado contexto histórico.

Ahora bien, entender el carácter intersubjetivo de la percepción y la capacidad de empatizar y comprender a otros en su propio universo de significaciones, supone que la distancia y perspectiva espacial desde donde nos situamos pueden ser superadas en alguna medida al entrar en el mismo contexto del otro; pudiendo así ver con la misma tipicidad de él, o por lo menos aproximándonos a esa mirada. Lo que también supone que, más allá de las diferencias entre las historias de vidas entre el que observa y el observado, ya contamos con un mundo ordenado y tipificado por medio de un lenguaje que compartimos, si bien no en todas sus 
significatividades particulares, -el argot o los localismos verbales- sí tenemos una fuerte base en común que permite la comprensión del otro.

Esta etapa es una dimensión fuerte y consistente. Para abordarla se ha diseñado un método de observación de la realidad en terreno y luego coordenadas específicas para transmitir esta experiencia en el aula como ejercicios individuales y grupales. Es necesario hacer la salvedad de que este método no busca en sus fundamentos ni en su práctica la observación de personajes y territorios de la realidad que pudieran servir de inspiración para la construcción de zonas y de personajes de ficción, sino que intenta contactar el cuerpo con lo que se construye en lo social. De esta forma se presenta la primera dificultad en el proceso de percibir desde lo social: ¿qué seleccionar?, ¿qué lugar y qué persona van a ser representadas? Precisamente porque esta elección no debe ser prejuiciada ni adjetivada, ni hecha desde una perspectiva cientificista que pretenda objetivar a los sujetos, debe ocurrir en la sensibilidad del estudiante para observar un contexto. Ya sean personas o situaciones conflictivas, este tiene necesariamente que recurrir a esta selección a partir de lo sensible en el campo de la percepción, planteándosele el desafío de conectar con lo dramático exterior a él y no con aquello que es sinónimo de camuflaje o superfluo. La observación de la vida social adquiere un fuerte compromiso interno, pues, el proceso de percibir, implica captar desde el propio sentir del sujeto investigado, incorporando en el que investiga los porqué de todo el accionar del otro investigado; accionar que integra la corporalidad, reconociendo tanto su particularidad física, como su historia de vida, contexto y todo otro tipo de variables que influyan sobre su forma de habitar en la realidad. A eso se suma todo el entramado social de relaciones y conflictos que se dan en torno al individuo observado. Esta dramaticidad artística conquistada por el estudiante, entonces, es la única capaz de generar el contacto posible para desarrollar el viaje orgánico capaz de seleccionar el drama donde estarán la persona y su entorno.

La siguiente dificultad una vez seleccionada y aprobada la persona a investigar y el entorno social en que ella está involucrada, es reproducir en el aula el resultado de esta investigación en terreno. Allí concurre una selección de todo aquello que ha sido percibido: gestos, actitudes, situaciones, sonidos, conflictos, palabras, olores, conversaciones, silencios, miradas, etc. Significa que todas esas texturas no siempre corresponden a una realidad dramática que puede ser internalizada como parte de la percepción dramática de lo real. 


\section{Precisiones, desafíos e interrogantes para este proceso perceptual en lo artístico}

Cuando se pasa al proceso de dramaturgización, se entra en la dimensión de la creación artística desde la percepción -que como se ha explicado, nunca será, en esta experiencia, el ámbito de creación artística desde lo ficcional- lo que importa, en un principio, es el contacto corporal con el contexto investigado.

Luego se procede a sumar las observaciones que cada uno de los estudiantes hace sobre su sujeto al trabajo colectivo y en donde cada investigación particular debe ser evaluada para integrarse al trabajo grupal. Si estas son aprobadas, se procede a unir todas las aristas del mismo contexto, donde ya comienzan a cotejarse percepciones más colectivas y elaboradas del lugar, sus conflictos, tipos de relaciones, distribución espacial y las diferentes personas a las cuales se les ha hecho seguimiento: individualidades que están unidas dramáticamente dentro de una realidad. Si los sujetos investigados no están unidos dramáticamente en el espacio real -sino anecdóticamente- el desafío es unirlos en la última etapa de creación, pero sin el ánimo de ficcionalizar o de ensamble: hacerlo desde coordenadas dramáticas que igual recorren e involucran a estas diferentes personas observadas ya que comparten profundas líneas dramáticas en ese contexto aunque ellas no lo sepan y que, sin embargo, el alumno ha debido percibir. Es este un tema complejo a la hora de dramaturgizar en la etapa final por parte del alumno, ya que puede derrumbarse el hondo edificio construido de la percepción dramática, siendo sustituido por la manipulación ficcional. Los ámbitos sociales donde los estudiantes han investigado en subgrupos y que en el proceso en terreno han ido seleccionando y, por tanto, han llevado al aula como una multiplicidad de materiales para la creación colectiva dramatúrgica desde la percepción, son ya el único recipiente que ha sobrevivido a un duro y sensible proceso orgánico. Proceso de contacto con lo social en donde tantas texturas de la realidad han quedado inevitablemente en el camino. La dramaturgización desemboca en una puesta en escena grupal donde ese universo de la vida cotidiana debe quedar artísticamente manifestado en el aula.

Es posible enunciar múltiples ejes que, constantemente, suponen la revisión y orientación del material observado, así como la permanente reflexión metodológica que surge cada vez que los alumnos proponen y desarrollan lugares, conflictos, personas a investigar. En este curso, no se recrea-interpreta sino se manifiesta un mundo dramático de lo social en el aula. Se comprende empáticamente el contexto cultural observado sin el objetivo de crear una puesta en 
escena como se entiende habitualmente, pero sí una creación dramatúrgica que se pone en escena, la que siempre es artística porque debe estar asociada a ese contacto progresivamente manifestado en el aula. Los estudiantes siempre tienen libertad de decidir, de ir en principio donde quieran, pero sin cálculo ficcional o artístico-estético de lo que al final se creará en escena como dramaturgia o incluso lo que resulta más atrayente o potenciante en lo histriónico.

Una pregunta clave recorre todo el proceso a la hora de diseñarlo y de guiarlo: ¿por qué contactaste con eso? Lo cual supone también la pregunta de ¿qué hay en ti sensorial y antropológicamente, que te ha hecho contactar y empatizar con aquello? Esto es una base fundamental de la percepción y de la decisión de elegir la persona, el lugar, la situación y el material dramático a observar en terreno y después manifestarlo progresivamente en el aula. El contacto perceptual con lo observado-investigado supone una profunda experiencia sensorial orgánica del cuerpo. La dramaticidad de eso percibido -seleccionado orgánicamente- es un punto de inflexión que determina este sentir y que solo ocurre en el marco de la experiencia orgánica. Esto es lo que se busca contactar en terreno y luego su manifestación fiel de ese contacto en el aula: esto es percepción dramática de lo social.

Todo acto dramático en la creación ficcional tiene una base en lo real, pues nada hay en el arte que no esté inspirado y luego elaborado, sea de un modo consciente o inconsciente, en la vida humana, social y subjetiva. Y esto independientemente de los parámetros de simbolización con que esta creación se desarrolla. Nos proponemos hacer consciente al estudiante que debe percibir, contactar con estas relaciones sociales, para luego ser un agente consciente que va a desarrollar sus técnicas, su experiencia en el mundo del oficio teatral en la profunda orientación de la creación estética y simbólica de esta relación dramática de lo real. Así como el director y el dramaturgo, independientemente de los estilos, parecieran por naturaleza propia ser más conscientes de esta necesidad, el estudiante de actuación debe hacerse también consciente de esto. Se constituye así en la materia prima de un actor que más adelante deberá abordar en profundidad los espacios de ficción. De esta forma esta experiencia nos plantea que el trabajo de percepción de la realidad nunca es creación ficcional; que el alumno, por medio de la implicación y las reiteradas ocasiones en que se va a terreno, es capaz de mostrar aquello que se contactó, reproduciendo en cuerpo y espacio de un modo artístico esa experiencia. Aquí, entonces, la ficcionalización representa un fracaso de lo perceptual y de la introyección de la experiencia orgánica de observar y de manifestar. Así, el contacto con lo 
investigado es un punto de acento y torcimiento artístico y técnico clave en este curso, pues el ejercicio es algo que se va mostrar en aula, lo que ya tiene siempre un componente de ficcionalización. Es este el problema que suele ocurrir, lo cual evaluativamente significa que el contacto que se hizo en terreno no fue desde lo perceptual, con las personas y con esas relaciones dramáticas culturales. Eso significa que no ha habido percepción, que es pues lo difícil del curso, un ejercicio que como tal debe ser preparado, mostrado, pero debe ser en esta perspectiva. Si el estudiante no logra comprender perceptualmente desde su organicidad a las personas y las relaciones dramáticas con las que debería haber contactado, esto es, de algún modo, un fracaso. El animus y el gesto que se deben percibir de un contexto exterior, esto es, su reconocimiento, pasa por el cuerpo y por la vivencia orgánica de ese contexto. El arte del entrenamiento de los sentidos, que corresponde al aprendizaje del cuerpo donde se reconozca dramáticamente lo social, es un proceso real-inductivo y, por tanto, no analítico. Los gestos observados, por ejemplo, son verificaciones de impulsos orgánicos que nos permiten reconocer alteraciones del propio cuerpo y recién desde allí se puede reconocer lo observado, entonces pasa por la propia organicidad.

\section{A modo de conclusión}

El curso de "Percepción Actoral", como se ha mencionado, en sus orígenes carga con una larga tradición arraigada en el compromiso social. Es por esto que cabe destacar que además de ser un puente para el estudiante en el involucramiento y, por lo tanto, en el conocimiento de otras realidades sociales, cumple con una de las funciones claves del teatro, esto es, reflexionar sobre el acontecer social. Reflexión, que para nuestra realidad latinoamericana (mágica como la han descrito algunos) no puede obviar los problemas de la exclusión, debido a una fuerte mercantilización de la sociedad, que para muchos sectores se da a modo de imposición. El inmiscuirse de nuestros jóvenes en una variada gama de contextos sociales, que ocasionalmente pueden ser de vulnerabilidad social o de estratos populares, cumpliría el papel de dar voz por medio de la representación, a los sin voz. Y esto se cumpliría correctamente, si los estudiantes pudieran llegar a un verídico proceso empático del contexto social que están observando. Los actores pueden ser claros agentes de reflexión de lo social, incluso de demandar o dar a conocer realidades que por medio de la actuación se hacen cercanas. Sin plantear una predisposición, es un hecho histórico que en este curso y también ahora mismo 
las personas y ámbitos de la sociedad que se investigan suelen pertenecer al universo de lo popular y de lo marginal. Por esto mismo puede dar voz a aquellos que no la tienen y tomar un carácter de meditación de lo social.

Este curso no busca enseñar el saber ser, pues sería materia para otra disciplina, pero sí estamos distanciados de una visión utilitarista que ha tomado lo económico, que cada vez prima más en las relaciones, por eso está la libertad de elección del contexto social investigado, pues claramente no ha sido una obligación o imposición del profesor llegar a lo popular, así este contacto se produce desde la propia motivación del estudiante, a veces logrando fuertes lazos que duran en el tiempo e incluso en ocasiones cambiando su percepción de lo social. Otra función importante es aquí su capacidad testimonial, pues el contexto social y un determinado momento histórico han quedado plasmados, además de que cada vez que se realiza el curso está la posibilidad de captar las diferentes formas de identidad que se conjugan en el entramado social. Así, el teatro cuando lleva a escena, reflecta la existencia de una particular identidad cultural. Por ende la reconoce y la constituye, cosa no menor si hablamos de contextos que socialmente son los menos visualizados. Este proceso en el actor y sobre todo en el actor que se está formando, se encarna en un autoaprendizaje, en un autoconocimiento sensorial, que quizás e idealmente puede estar al servicio de una realidad, a la que el estudiante va a ir sin prejuicios, humildemente, a observar, a conocer para luego participar de la profunda dificultad y desafío de escenificarla en su persona, aprendiendo a conocer su cuerpo y sus sentidos, a conocer su propia identidad al reconocer otra. La realidad social tiene ahora un valor diferente.

\section{Referencias}

BARBA, Eugenio. La canoa de papel: tratado de antropología teatral. Buenos Aires: Catálogos, 2009.

CALLERY, Dympha. Through the body: a practical guide to physical theatre. New York: Routledge, 2001.

NOGUERA, Héctor. La relación observación-imitación: punto de partida de lo teatral. Apuntes, n. 95, p. 79-85, 1987.

NOGUERA, Héctor; OSORIO, Raúl. La percepción teatral: orientaciones para la formación actoral. Proyecto de Investigación DIUC N 149/85. Santiago de Chile: Pontificia Universidad Católica, 1987.

OSORIO, Raúl. El desarrollo del actor. Apuntes, n. 98, p. 102-111, 1989.

OSORIO, Raúl. La doble naturaleza del actor: vidente y artesano. Apuntes, n. 100, p. 136-138, 1990.

PRIOR, Ross. Teaching Actors: Knowledge Transfer in Actor Training. Bristol, UK: Intellect, 2012.

SHUSTERMAN, Richard. Thinking through the Body: Essays in Somaesthetics. Cambridge: Cambridge University Press. 2012. 